\title{
Psychological Factors Linking Perceived CSR to OCB: The Role of Organizational Pride, Collectivism, and Person-Organization Fit
}

\author{
Eaint Yadanar Oo ${ }^{1}$, Heajung Jung ${ }^{2, *}$ and In-Jo Park ${ }^{3}$ \\ 1 Business School, Korea University; 145 Anam-ro, Seongbuk-gu, Seoul 02841, Korea; shanpoepoe@gmail.com \\ 2 School of Business, Konkuk University, 120 Neungdong-ro, Gwanjin-gu, Seoul 05029, Korea \\ 3 Department of Psychology, Henan University, 1 Jinming St., Kaifeng 475004, Henan, China; \\ park@henu.edu.cn \\ * Correspondence: heajung@konkuk.ac.kr; Tel.: +82-2-450-3634
}

Received: 5 June 2018; Accepted: 11 July 2018; Published: 16 July 2018

\begin{abstract}
Despite a growing amount of research on the impact of perceived corporate social responsibility (CSR) on employee behavior, psychological factors explaining why and for whom the relationship holds have yet to be fully investigated. Drawing on social identity theory, this study examined organizational pride as the underlying psychological mechanism explaining the relationship between CSR perception and organizational citizenship behavior (OCB), and tested the moderating effects by two individual difference variables: collectivism orientation and person-organization fit. Analyses of survey data collected from 210 employees in South Korea showed that organizational pride mediated the CSR perception-OCB relationship. In addition, collectivism orientation strengthens the CSR-pride relationship, while person-organization fit strengthens the OCB-pride relationship. This research contributes to the relevant literature by stressing the importance of individual characteristics in predicting and understanding the effects of CSR perception on employee behavior.
\end{abstract}

Keywords: CSR perception; organizational citizenship behavior; organizational pride; collectivism; person-organization fit

\section{Introduction}

In this era where creativity and innovation are highlighted as intangible assets of an organization [1], the survival and growth of an organization cannot be achieved without its employees' active engagement and strong dedication. In other words, in order to build a successful and sustainable organization, employees must be willing to perform more than the minimal, formal, and specified technical aspects of their jobs and voluntarily engage in extra-role behavior [2]. Organizational citizenship behavior (OCB) depicts such spontaneous employee behavior promoting the efficient and effective functioning of the organization [3]. What makes employees voluntarily engage in citizenship behavior such as helping other employees, putting extra effort into achieving better performance even when no formal reward system is in place, or trying not to waste time at work? One important but relatively less studied determinant of employee behavior is the employees' emotions toward their organization. Emotional responses to one's company can be as strong drivers of one's behavior as cognitive perceptions of one's organization such as perceived organizational support or perceived justice [4].

It is generally expected that positive feelings toward one's organization would lead employees to more constructive work behavior. For employees who spend a considerable amount of time at work and build their career upon work experiences, how they feel about their employer can impact 
their self-esteem (i.e., organization-based self-esteem) [5]. According to social identity theory [6], an individual's identity partly stems from their social identity such that their self-concept derives from their group membership along with the value and emotional significance attached to that membership. If an employee works for a company with a good reputation and prestigious status in that society, it will boost their pride in their group membership, which in turn will enhance positive employee behavior at work [7].

One factor that is closely related to an organization's reputation and prestige is corporate social responsibility (CSR) activities. Since the occurrence of corporate scandals involving unethical and irresponsible management activities, the level of social awareness has been heightened, and collective monitoring activities on business practices have been accelerated in order to ensure ethical business practices. The degree to which an organization is committed to various CSR activities has become a useful barometer of organizational efforts to develop win-win relationships with its stakeholders and build a sustainable business model. Prior empirical studies have shown that when employees, as internal stakeholders, perceive their organization's CSR activities, it creates a sense of organizational pride [7-9]. In this research, we aimed to examine the effect of employees' CSR perception on their engagement in $\mathrm{OCB}$, and further investigated organizational pride as the underlying psychological mechanism.

In addition, the extent to which the hypothesized relationship (from CSR to organizational pride to OCB) manifests itself can differ by employees' individual characteristics. In this paper, we examined two individual difference variables—collectivism and person-organization fit-as two potential moderators. First, collectivism (versus individualism), which is well known as a dimension describing national culture, can be measured as multidimensional constructs depicting individual values [10]. For instance, employees in Korea can vary in collectivism orientation despite living in a collectivistic culture. We expect that employees high in collectivism orientation will experience organizational pride more intensely in response to their CSR perception. In predicting OCB, another moderator, person-organization fit (P-O fit), is expected to influence the impact of organizational pride. When employees perceive value congruence between personal values and the values of their organization, feeling proud about their group will lead to active engagement in OCB. Our research model is depicted in Figure 1. By exploring the psychological mechanism and the interplay of individual characteristics, we expect this research to expand our knowledge on why and for whom CSR perception matters and promotes OCB.

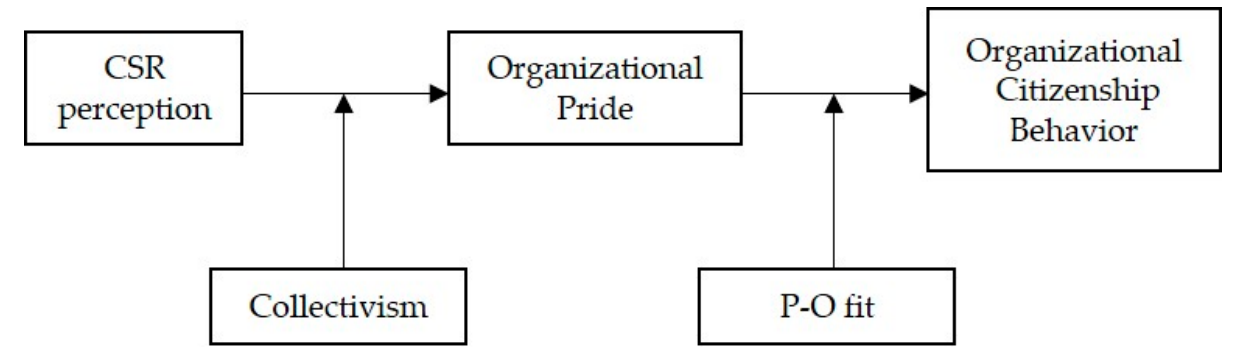

Figure 1. Research model.

\section{Theoretical Background and Hypotheses}

\subsection{CSR Perception and $O C B$}

A growing number of organizations implement CSR activities as an attempt to meet the social expectation of business ethics, build win-win relationships with external and internal stakeholders, and ultimately achieve profitable and sustainable business growth $[9,11,12]$. Corporate social responsibility refers to "a business entity's attention to and fulfillment of responsibilities to multiple stakeholders" [13]. According to Carroll (1991) [14], CSR is classified into four categories: economic, 
legal, ethical, and philanthropic responsibility. These four categories of responsibility refer to (1) generating profitable returns for shareholders, (2) abiding by the law, (3) protecting moral rights and pursuing fairness and transparency in business practices, and (4) embracing responsibilities that are demanded or prohibited by society, respectively.

On the other hand, Brammer et al. (2007) [11] distinguished CSR into external CSR and internal CSR. The former refers to the responsibility in relation to external constituencies such as local communities, while the latter refers to the responsibility within the internal operation of the organization. While early studies into the consequences of CSR activities have paid more attention to external stakeholders such as customers $[15,16]$, recently, a growing number of research has begun to examine the impact of CSR on internal stakeholders: its employees $[17,18]$.

In this research, we examined the effect of perceived CSR on OCB. Organ (1988) [3] defined OCB as "individual behavior that is discretionary, not directly or explicitly recognized by the formal reward system, and in the aggregate promotes the efficient and effective functioning of the organization". OCB can be also classified into five categories: (1) conscientiousness: employees perform individual tasks well above the minimum required levels, (2) altruism: employees are willing to help their colleagues, (3) civic virtue: employees responsibly participate in the political life of the organization, (4) sportsmanship: employees do not complain, but rather have positive attitudes toward their work and organization, and (5) courtesy: employees treat each other with respect. OCB can be also grouped into two broad categories according to the target of behavior: (a) OCB-O, which is behavior that benefits the organization in general, and (b) OCB-I, which is behavior that immediately benefits specific individuals and indirectly contributes to the organization [19]. Smith, Organ, and Near (1983) [20] labeled the OCBI dimension altruism, and the OCBO dimension generalized compliance.

Then, how would employees' CSR perception affect their OCB? A couple of causal mechanisms can be proposed to predict the positive effect of CSR perception on OCB. First, a feeling of accountability for personal actions that is consistent with the organization's citizenship behavior might encourage employees to show more citizenship behavior [21]. Once employees perceive their employer's efforts to be a responsible citizen, they tend to include citizenship behavior in their work role responsibilities. Another relevant theory is social learning theory [22], where it is argued that behavioral expectations and norms are learned through observing role models. In an organization where socially responsible actions are valued, emphasized, and regarded as normative standards of conduct, employees will model those behaviors displayed by the management and leaders in their own actions [21]. Thus, we hypothesize that employees' CSR perception will enhance their engagement in OCB.

\section{Hypothesis 1. Employees' CSR perception will have a positive relationship with employees' OCB.}

\subsection{Organizational Pride as a Mediator}

Pride is defined as a self-conscious emotion involving complex self-evaluative processes [23]. It is elicited by one's own or others' achievement and associated with self-esteem and positive self-image [24]. In a work setting, two forms of pride can be identified [25]. Personal pride is elicited by individual achievements such as a sense of one's value from a good deed [23]. Collective pride can be experienced when employees perceive group achievements and feel a sense of affiliation and identification with their group/organization even without their personal achievement being involved [26]. Aside from the company's achievements, the company's market position, image, corporate reputation, management's leadership style, and creation of a challenging work environment are all regarded as potential sources of organizational pride $[5,25,27,28]$.

Prior research has revealed that employee CSR perception can boost their experience of pride in membership [7,9]. De Roeck et al. [7] explained why knowing that one's organization carries out CSR activities makes employees feel proud about being a member of it by showing the mediating role of perceived external prestige. Companies who actively pursue CSR activities tend to be seen as more responsible, distinctive, and prestigious by outsiders. When employees know that outsiders view and 
evaluate their organization in a positive light, it enhances their self-esteem [29] and sense of self-worth. This is explained by social identity theory, which posits that individuals define themselves in terms of the social groups that they belong to [6]. If their group or organization enjoys a favorable reputation and prestigious status, it carries over to one's self-esteem and brings about feelings of pride.

Tyler and Blader (2002) [30] posited that pride could lead to a range of behaviors that benefited the organization. An employee's organizational pride affects the performance more strongly when compared to their personal pride [31]. It has been found that an employee's organizational pride has a positive effect on their behavior such as intention to stay, commitment, job satisfaction, cooperation, and creativity $[17,25,32]$. In this paper, we propose that organizational pride is a psychological mechanism underlying the relationship between CSR perception and OCB and examine its mediation effect.

\section{Hypothesis 2. Organizational pride will mediate the relationship between CSR perception and OCB.}

\subsection{Collectivism Orientation as a Moderator}

Although it appears intuitively appealing to consider individual differences to predict a person's decision to perform citizenship behaviors, individual difference variables have gained less attention than contextual variables. However, there exists evidence that individual differences account for significant amounts of variance in OCB [33]. According to Rioux and Penner (2001) [33], employees are motivated to engage in OCB because of organizational concern, prosocial values, and impression management. Organizational concern describes the employees' desire to see their company do well and show their pride in and commitment to the organization. Prosocial values represent a desire to be helpful and to create constructive relationships with other people. Impression management indicates a desire to avoid looking bad to colleagues and supervisors and obtain rewards. Relative to the other motives, prosocial value motives were more strongly associated with OCB directed at individuals (OCB-I), and organizational concern motives were more strongly associated with OCB directed toward the organization (OCB-O).

Just as a person's values such as prosocial values can predict the likelihood of an individual to engage in OCB, it has been found that individual differences in collectivism and individualism also significantly predict employee behavior, including OCB [34,35]. Hofstede (1980) [36] originally conceptualized individualism-collectivism as a bipolar, unidimensional variable that distinguishes national cultures. However, Triandis, McCusker, and Hui (1990) [37] suggested that individualism-collectivism can be regarded as a multidimensional construct at the individual level. More specifically, both individualism and collectivism can coexist within an individual; that is, a person can exhibit high or low on both, or high on one and low on the other at different times or in different situations. Therefore, it is inaccurate to presume whether an individual is collectivistic or individualistic by only looking at the country origin.

Furthermore, Triandis and Gelfand (1998) [10] argued that these values can be further divided by the relative emphasis on horizontal and vertical social relationships. Combining this new horizontal-vertical distinction with the collectivism-individualism dimensions yields four distinct patterns: vertical collectivism (VC), horizontal collectivism (HC), vertical individualism (VI), and horizontal individualism (HI). A horizontal self-concept emphasizes oneself more or less similar to others, while a vertical self-concept views oneself as different from others in hierarchical relationships. In HI, being unique and distinct from groups is valued, while in VI, competing with others, being distinguished, and having a high status is a matter of concern. Similarly, in HC, common goals with others and interdependency/sociability are of interest, whereas in VC, integrity of the in-group and sacrifice of personal interests for the sake of the group is taken for granted [38]. Triandis and Gelfand (1998) [10] confirmed that these four patterns were meaningfully observed in Korea, which has a collectivist culture.

In this research, we attempt to examine employees' collectivism orientation because it is expected to affect the extent to which employees identify with their employer and accordingly feel pride in their membership when their employer is seen as a socially responsible citizen. Little is known about how individual characteristics such as collectivism orientation interact with employees' CSR 
perception. In a study conducted by Korean scholars [39], it was reported that the relative effects of multidimensional CSR types on corporate reputation differed by the individualism versus collectivism orientation. Researchers also pointed out that in a collectivistic culture, Confucian thinking and social legitimacy might have an impact on the effect of CSR activities on employees in Korean corporations [40].

When it comes to organizational pride, earlier studies on Chinese and American participants found that individuals high in collectivism orientation would be more likely to feel collective pride rather than personal pride derived from their self-achievements [41]. In a similar vein, we assumed that employees with collectivism orientation would experience a higher level of organizational pride if they perceived the CSR activities of their organization and anticipated a good reputation. Therefore, we hypothesize the moderating effect of collectivism in the relationship between CSR perception and organizational pride as follows:

Hypothesis 3. Employee's collectivism orientation will moderate (enhance) the relationship between CSR perception and organizational pride such that the positive relationship will become stronger for those with high collectivism orientation.

\subsection{Person-Organization Fit as a Second Moderator}

In order to fully understand and better predict employee behavior in organizations, the interaction effects of person and situation factors must be put into consideration. Katz and Kahn (1978) [42] indicated that value was one of the most fundamental and enduring aspects for both organizations and people. The person-organization fit model treats organization values and norms as the situational factor while examining individual values and personality characteristics as the personal factor. A higher level of person-organization fit exists when there is congruence between the norms and values of organizations and the values of individuals [43].

Two distinctions have been proposed in an attempt to clarify multiple conceptualizations of $\mathrm{P}-\mathrm{O}$ fit. The first distinction is supplementary versus complementary fit [44-46]. Supplementary fit occurs when a person's characteristics are similar to others' in the organization, as in the case of value congruence and goal congruence. Complementary fit occurs when a person's characteristics fill in what the organization lacks. P-O fit falls in the category of supplementary fit, while other types of fit such as person-job fit are regarded as complementary fits. A second perspective on $\mathrm{P}-\mathrm{O}$ fit is offered by the needs-supplies and demands-abilities distinction. From the needs-supplies perspective, it is suggested that $\mathrm{P}-\mathrm{O}$ fit exists when the organization can supply the needs of employees. In contrast, from the demands-abilities perspective, $\mathrm{P}-\mathrm{O}$ fit is observed when an individual has the abilities that are required to perform organizational demands. Kristof (1996) [46] defined the P-O fit as "the compatibility between people and organizations that occurs when: (a) at least one entity provides what the other needs, (b) they share similar fundamental characteristics, or (c) both".

It has been shown that person-organization fit significantly predicts employee behavior at work [47,48]. Chatman (1991) [49] demonstrated that value congruence between individuals and organizations can predict outcomes such as adjustment, job satisfaction, organizational commitment, intent to stay, tenure, and turnover. Moreover, person-organization fit perceptions are related to organization-focused outcomes such as organizational identification, $\mathrm{OCB}$, turnover decisions, and job satisfaction [50]. On the other hand, if the person-organization fit is low, we can predict three immediate outcomes: the person's values could change and become more similar to the organization's, the organization's values could change, or the person could leave the organization [43]. Too much incompatibility can produce lethargic and unmotivated individuals [51].

Self-identity theory may help explain why $\mathrm{P}-\mathrm{O}$ fit can shape individual behavior in an organization. When employees perceive a good fit with their organization, they build up a high level of identification with their organizations [50] and are more likely to engage in extra-role behaviors. A high $\mathrm{P}-\mathrm{O}$ fit makes employees believe anything that is good for the organization will be also good for them through 
a strong identification with the organization, thereby leading employees to show more citizenship behavior than those experiencing a lower level of $\mathrm{P}-\mathrm{O}$ fit. When predicting that organizational pride will increase $\mathrm{OCB}$, we expect that the individual difference in $\mathrm{P}-\mathrm{O}$ fit determines the strength of the relationship. Employees who perceive a good fit between what they value and what their organization values will tend to agree more with the messages sent by the organization [44]. The message delivered through the employer's involvement in CSR activities is that we should be a responsible member of our community. High $\mathrm{P}-\mathrm{O}$ fit employees understand the message better and support it by putting it into action in their work life, which could be displayed as a form of OCB. Even when a similar level of organizational pride is experienced by perceived CSR, the extent to which pride leads to actual behavior such as OCB will depend on the level of $\mathrm{P}-\mathrm{O}$ fit that each employee perceives. This leads to the formulation of our final hypothesis:

Hypothesis 4. Person-organization fit will moderate (enhance) the relationship between organizational pride and OCB such that the positive relationship will become stronger for employees who perceive a higher level of $\mathrm{P}-\mathrm{O}$ fit.

\section{Research Method}

\subsection{Sample and Procedures}

Data was collected via an online survey questionnaire in South Korea between September and October in 2016. We collaborated with an online survey firm who manages a large pool of survey participants. Upon our request, they sent out a survey invitation to 4685 individuals in their participant pool, and 830 individuals initiated the survey in response to the invitation. A couple of initial screening questions were asked to exclude respondents who were not relevant to our study (e.g., individuals who are self-employed or unemployed). In total, 263 respondents passed the screening procedure and completed the survey to the end. Respondents' employers belonged to diverse industries such as manufacturing $(41.9 \%)$, information technology (IT) $(24.8 \%)$, service $(19.5 \%)$, retail $(7.6 \%)$, etc. Additionally, 53 responses were further removed before data analysis due to too many incomplete responses, which left 210 responses as our final dataset.

A frequency analysis conducted with the final dataset $(N=210)$ showed that $59.5 \%$ of the respondents were male (125 respondents). In terms of age, the respondents under 30 comprised $21.4 \%$ of the sample ( 45 respondents), those in their 30 s represented $35.2 \%$ (74 respondents), those in their $40 \mathrm{~s}$ represented $37.6 \%$ (79 respondents), and those in their $50 \mathrm{~s}$ represented $5.7 \%$ (12 respondents). The majority of the respondents $(73.8 \%, 155$ respondents) had a college degree, while $7.1 \%$ were high school graduates (15 respondents), and 19\% were graduate degree holders (40 respondents). Regarding tenure in the current organization, respondents had a various number of years such as less than one year $(16.7 \%)$, two to three years $(19.5 \%)$, four to five years $(14.8 \%)$, six to 10 years $(27.1 \%)$, and more than 10 years $(21.9 \%)$. The size of the company (for which the respondents worked) varied such that about $31.9 \%$ of the respondents worked for a large company, $27.1 \%$ worked for an enterprise of middle standing, and the remaining $41 \%$ worked for a small or medium-sized business.

\subsection{Measures}

All items of the following measures were answered on a five-point Likert scale from 1 ("strongly disagree") to 5 ("strongly agree"). The survey items are listed in Appendix A.

\subsubsection{CSR Perception}

Following Maignan and Ferrell (2004) [52], we defined perceived CSR as the perception of organizational activities that support social causes such as public services, sponsorship donations, and voluntary works in addition to the pursuit of economic profits for the corporation. We measured perceived corporate social responsibility by using four items [53] that were developed based on the 
previous work of Maignan and Ferrell (2004) [52]. Sample items are "My company helps solving social problems" and "My company participates in public beneficial activities" $(\alpha=0.92)$.

\subsubsection{Organizational Pride}

We defined organizational pride as a feeling of pride elicited by organizational membership [29]. We measured organizational pride by using a four-item scale developed by Lee and Cho (2013) [54], which drew on earlier works by Tyler and Blader (2002) [30] and Boezeman and Ellemers (2007) [55]. Sample items include "I am proud of being a member of my company" and "I feel proud of telling other people that I am being a part of my company" $(\alpha=0.90)$.

\subsubsection{Organizational Citizenship Behavior (OCB)}

We adopted the definition of OCB by Organ (1988): “individual behavior that is discretionary, not directly or explicitly recognized by the formal reward system, and in the aggregate promotes the efficient and effective functioning of the organization" [3]. In addition, we followed Williams and Anderson (1991)'s approach [19], where OCB can be divided into either OCB-I, which is behavior that immediately benefits specific individuals, or OCB-O, which is behavior that benefits the organization in general. Therefore, we measured OCB by using an eight-item scale [56] that consisted of four items measuring OCB-I and four items measuring OCB-O. Examples include "Helps others even though there is no formal request" (OCB-I) and "Don't waste the office hours with personal business" (OCB-O) $(\alpha=0.87)$.

\subsubsection{Collectivism Orientation}

Collectivism orientation was measured by the items modified by Kim and Park (2014) [39] on the basis of the work of Triandis and Gelfand (1998) [10]. We selected the four items measuring horizontal collectivism, since they describe the value of appreciating group harmony within the work setting, while items measuring vertical collectivism primarily ask about family relationships (e.g., "Family members should stick together, no matter what sacrifices are required"). Considering that our target participants were employees and the variables of interest are related to work life, we concluded that horizontal collectivism (HC) would be a more appropriate dimension for our study. HC is defined as a tendency to "see themselves as being similar to others and emphasize common goals with others, interdependence, and sociability" [10]. Sample items are "If a coworker gets a prize, I would feel proud" and "I feel good when I cooperate with others" $(\alpha=0.83)$.

\subsubsection{Person-Organization Fit}

$\mathrm{P}-\mathrm{O}$ fit is defined as "employees' subjective beliefs about how well their personal characteristics match the organizational culture" [46,50]. We measured the person-organization fit using the five-item scale developed by Choi, Jang, and Kwun (2011) [57] such as "The values I preferred are consistent with our company's organizational values" and "Company adaptation is hard for me because my values differ greatly from the company's values" $(\alpha=0.90)$.

\subsubsection{Control Variables}

As control variables, we included gender, age, education level, and tenure in their current organization. These variables were collected using self-report questions.

\section{Results}

\subsection{Confirmatory Factor Analysis}

First, we conducted confirmatory factor analysis (CFA) using SPSS AMOS 18 to assess the validity of the measurement scales of study variables. The CFA results are summarized in Table 1. Overall, the five-factor measurement model achieved an acceptable good fit $\left(\chi^{2}=428.452, d f=261\right.$, TLI $=0.94$, 
$\mathrm{CFI}=0.95, \mathrm{RMSEA}=0.06$ ). When comparing the research model with three alternative models (four-, three-, one-factor model) respectively, chi-square difference tests were all significant and the alternative models all showed sub-standard absolute fit levels. This confirms the discriminant validity of our research variables and weakens the possibility of common method bias.

Table 1. Confirmatory factor analysis.

\begin{tabular}{lcccccc}
\hline \multicolumn{1}{c}{ Model } & $\chi^{2}$ & $d f$ & TLI & GFI & CFI & RMSEA \\
\hline Research Model (five factors) $^{2}$ & $428.452^{* * *}$ & 261 & 0.94 & 0.87 & 0.95 & 0.06 \\
Alternative Model 1 (four factors) $^{\mathrm{a}}$ & $784.474^{* * *}$ & 269 & 0.83 & 0.73 & 0.85 & 0.10 \\
Alternative Model 2 (three factors) $^{\mathrm{b}}$ & $829.578^{* * *}$ & 272 & 0.82 & 0.73 & 0.84 & 0.10 \\
Alternative Model 3 (one factor) $^{\mathrm{c}}$ & $1416.475^{* * *}$ & 275 & 0.64 & 0.52 & 0.67 & 0.14 \\
\hline
\end{tabular}

Note: TLI = Tucker-Lewis Index; GFI = Goodness of Fit Index; CFI = Comparative Fit Index; RMSEA = Root Mean Square Error of Approximation; *** $p<0.001$. ${ }^{\text {a }}$ Collectivism and person-organization $(\mathrm{P}-\mathrm{O})$ fit were combined into a single factor. ${ }^{b}$ Collectivism, $\mathrm{P}-\mathrm{O}$ fit, and organizational pride were combined into a single factor. ${ }^{\mathrm{c}}$ All five factors were combined into a single factor.

\subsection{Correlational Analysis}

Table 2 presents the correlation matrix of the variables included in this study. First, the reliability indices, the Cronbach's alpha values of the measures of five variables, are listed in parentheses. The values ranged from 0.83 to 0.92 , which confirmed that the internal reliabilities of all five measures were acceptable. Out of four control variables, the respondents' age and education had significant positive relationships with the study variables. This showed that the older and the more educated the employee, the higher their CSR perception, organizational pride, $\mathrm{OCB}$, collectivism, and $\mathrm{P}-\mathrm{O}$ fit became. On the other hand, gender was negatively associated with OCB and collectivism. As male was coded as 1 and female was coded as 2 , the negative relationship indicates that female employees tended to show less collectivism and less citizenship behavior than male employees.

Table 2. Correlations. CSR: corporate social responsibility; OCB: organizational citizenship behavior.

\begin{tabular}{|c|c|c|c|c|c|c|c|c|c|c|}
\hline & 1 & 2 & 3 & 4 & 5 & 6 & 7 & 8 & 9 & 10 \\
\hline 1. Gender & 1 & & & & & & & & & \\
\hline 2. Age & $-0.41 * *$ & 1 & & & & & & & & \\
\hline 3. Education & $-0.16^{*}$ & 0.02 & 1 & & & & & & & \\
\hline 4. Tenure & $-0.24 * *$ & $0.47^{* *}$ & -0.04 & 1 & & & & & & \\
\hline 5. Firm size & -0.07 & 0.10 & $0.21 * *$ & $0.28^{* *}$ & 1 & & & & & \\
\hline 6. CSR & -0.12 & $0.21 * *$ & $0.22 * *$ & $0.16 *$ & $0.38^{* *}$ & $(0.92)$ & & & & \\
\hline 7. Pride & -0.09 & $0.18 *$ & $0.24 * *$ & 0.04 & $0.22 * *$ & $0.65 * *$ & $(0.90)$ & & & \\
\hline 8. OCB & $-0.14 *$ & $0.24 * *$ & $0.23 * *$ & 0.03 & $0.19 * *$ & $0.43 * *$ & 0.53 ** & $(0.87)$ & & \\
\hline 9. Collectivism & $-0.16^{*}$ & $0.27^{* *}$ & $0.26 * *$ & 0.11 & $0.19 * *$ & $0.47^{* *}$ & $0.46^{* *}$ & $0.71 * *$ & $(0.83)$ & \\
\hline 10. P-O fit & -0.08 & $0.20 * *$ & $0.25^{* *}$ & 0.07 & $0.22 * *$ & $0.63^{* *}$ & $0.80 * *$ & $0.54^{* *}$ & $0.43^{* *}$ & $(0.90)$ \\
\hline
\end{tabular}

* Correlation is significant at 0.01 levels (two-tailed); ${ }^{* *}$ Correlation is significant at 0.05 levels (two-tailed).

\subsection{Hypotheses Testing}

Hierarchical regression analysis was conducted to test Hypothesis 1 and Hypothesis 2. As shown in Table 3, the first hypothesis-that employees' CSR perception will be positively related to OCB-was tested by regressing OCB on the control variables first (Model 3) and entering CSR perception next (Model 4). First, age $(\beta=0.269, p<0.01)$ and education level $(\beta=0.219, p<0.01)$ had a positive impact on OCB, indicating that older employees and employees with higher education level tended to display more OCB. Controlling for the effects of the control variables, CSR perception was a significant predictor of OCB $(\beta=0.370, p<0.001)$, which supports Hypothesis 1 . 
Table 3. Regression analysis testing the mediation by organizational pride with CSR perception as an independent variable (IV) and OCB as a dependent variable (DV).

\begin{tabular}{|c|c|c|c|c|c|}
\hline \multirow[t]{2}{*}{ Variable } & \multicolumn{2}{|c|}{$\begin{array}{l}\text { Dependent Variable: } \\
\text { Organizational Pride }\end{array}$} & \multicolumn{3}{|c|}{ Dependent Variable: OCB } \\
\hline & Model 1 & Model 2 & Model 3 & Model 4 & Model 5 \\
\hline Gender & 0.02 & 0.02 & -0.02 & -0.02 & -0.03 \\
\hline Age & 0.20 * & 0.09 & $0.28^{* *}$ & $0.21^{* *}$ & $0.18^{*}$ \\
\hline Education level & $0.20 * *$ & $0.10 *$ & $0.18 * *$ & $0.13 *$ & 0.09 \\
\hline Tenure & -0.10 & -0.08 & -0.14 & -0.13 & -0.10 \\
\hline Firm size & $0.19 * *$ & -0.02 & $0.17^{*}$ & 0.05 & 0.06 \\
\hline CSR perception & & $0.63^{* * *}$ & & $0.35^{* * *}$ & 0.11 \\
\hline Org pride & & & & & $0.40^{* * *}$ \\
\hline$R^{2}$ & 0.12 & 0.44 & 0.14 & 0.24 & 0.33 \\
\hline$\Delta R^{2}$ & & 0.32 & & 0.10 & 0.09 \\
\hline$F$ for $\Delta R^{2}$ & & $114.26^{* * *}$ & & $26.96^{* * *}$ & $26.42^{* * *}$ \\
\hline Overall $F$ & $5.52^{* * *}$ & $26.20^{* * *}$ & $6.61^{* * *}$ & $10.70^{* * *}$ & $14.10^{* * *}$ \\
\hline
\end{tabular}

Hypothesis 2 examines the role of organizational pride as a mediator. In order to test the mediation effect, we employed the three-step procedure described by Baron and Kenny (1986) [58]. First, the relationship between independent variable and dependent variable has already been confirmed in Hypothesis 1. Next, Model 2 in Table 3 examines the effect of the independent variable on the mediator. The result showed that CSR perception is a significant predictor of organizational pride $(\beta=0.621$, $p<0.001)$. Last, in Model 5 , the independent variable and mediation variable were entered into the regression model simultaneously. When organizational pride was added to the regression equation, it was found that the effect of CSR perception on OCB became non-significant $(\beta=0.125, p=$ n.s.), while organizational pride had a significant effect on OCB $(\beta=0.393, p<0.001)$, The Sobel test on this mediation effect showed a significant result $(\mathrm{z}=4.55, p<0.001)$, which confirmed a full mediation effect by organizational pride.

As another way of testing the mediation effect, we conducted the bootstrapping method with bias-corrected confidence estimates [59]. The results of the mediation analysis confirmed the mediation role of organizational pride in the relationship between CSR perception and OCB $(B=0.17, C I=$ 0.10 to 0.26 ). In addition, the results indicated that the direct effect of CSR perception on OCB became non-significant $(B=0.09, t(208)=1.95, p=0.052, C I=-0.0006$ to 0.19$)$ when controlling for organizational pride, which supports Hypothesis 2.

Hypothesis 3 proposed a moderating effect of collectivism orientation on the relationship between CSR perception and organizational pride. A hierarchical regression analysis was performed, as shown in Table 4. The interaction term of CSR perception and collectivism showed a significant positive effect $(\beta=0.19, p<0.05)$, which suggests that the positive relationship between CSR perception and organizational pride becomes stronger when an employee's collectivism becomes higher. Therefore, Hypothesis 3 was supported. Following the suggestion by Aiken and West (1991) [60], the interaction effect was plotted in Figure 2.

Similarly, another hierarchical regression analysis was conducted to examine the fourth hypothesis that proposed the moderation effect by person-organization fit on the relationship between organizational pride and OCB. As presented in Table 3 , the interaction term was statistically significant $(\beta=0.18, p<0.05)$. The direction of moderation confirmed that the positive effect of organizational pride on OCB became stronger when employees perceived a better $\mathrm{P}-\mathrm{O}$ fit. Figure 3 graphically depicts the interaction effect of organizational pride and person-organization fit on OCB. 
Table 4. Results of hierarchical regression analyses predicting organizational pride and OCB.

\begin{tabular}{|c|c|c|c|c|c|c|}
\hline & \multicolumn{2}{|c|}{ Model 1} & \multicolumn{2}{|c|}{ Model 2} & \multicolumn{2}{|c|}{ Model 3} \\
\hline & $\beta$ & S.E. & $\beta$ & S.E. & $\beta$ & S.E. \\
\hline \multicolumn{7}{|c|}{ Dependent Variable: Organizational Pride } \\
\hline \multicolumn{7}{|l|}{ Step 1} \\
\hline Gender & 0.02 & 0.13 & 0.03 & 0.10 & 0.04 & 0.10 \\
\hline Age & 0.20 * & 0.08 & 0.06 & 0.06 & 0.06 & 0.06 \\
\hline Education & $0.20 * *$ & 0.12 & 0.07 & 0.10 & 0.08 & 0.09 \\
\hline Tenure & -0.10 & 0.05 & -0.08 & 0.04 & -0.07 & 0.04 \\
\hline Firm size & $0.19 * *$ & 0.07 & -0.02 & 0.06 & -0.03 & 0.06 \\
\hline \multicolumn{7}{|l|}{ Step 2} \\
\hline Corporate Social Responsibility (A) & & & $0.56^{* * *}$ & 0.06 & $0.54^{* * *}$ & 0.06 \\
\hline Collectivism (B) & & & $0.18^{* *}$ & 0.09 & $0.21^{* *}$ & 0.09 \\
\hline \multicolumn{7}{|l|}{ Step 3} \\
\hline$A \times B$ & & & & & $0.12 *$ & 0.07 \\
\hline$R^{2}$ & 0.12 & & 0.46 & & 0.47 & \\
\hline$F$ & $5.52 * * *$ & & $24.54 * * *$ & & $22.55 * * *$ & \\
\hline$\Delta R^{2}$ & & & 0.34 & & 0.01 & \\
\hline$\Delta F$ & & & $63.59^{* * *}$ & & $5.15 *$ & \\
\hline \multicolumn{7}{|l|}{ Dependent Variable: OCB } \\
\hline \multicolumn{7}{|l|}{ Step 1} \\
\hline Gender & -0.02 & 0.09 & -0.05 & 0.08 & -0.03 & 0.08 \\
\hline Age & $0.28 * *$ & 0.06 & $0.16^{*}$ & 0.05 & $0.16^{*}$ & 0.05 \\
\hline Education & $0.19 * *$ & 0.08 & 0.07 & 0.07 & 0.06 & 0.07 \\
\hline Tenure & -0.14 & 0.03 & -0.10 & 0.03 & -0.09 & 0.03 \\
\hline Firm size & $0.17 *$ & 0.05 & 0.07 & 0.04 & 0.07 & 0.04 \\
\hline \multicolumn{7}{|l|}{ Step 2} \\
\hline Organizational Pride (A) & & & $0.22 *$ & 0.07 & $0.24 *$ & 0.07 \\
\hline Person-Organization Fit (B) & & & $0.30 * *$ & 0.08 & $0.32 * *$ & 0.08 \\
\hline \multicolumn{7}{|l|}{ Step 3} \\
\hline$A \times B$ & & & & & $0.18^{* *}$ & 0.04 \\
\hline$R^{2}$ & 0.14 & & 0.35 & & 0.39 & \\
\hline$F$ & $6.61^{* * *}$ & & $15.83^{* * *}$ & & $15.75^{* * *}$ & \\
\hline$\Delta R^{2}$ & & & 0.22 & & 0.03 & \\
\hline$\Delta F$ & & & $33.61^{* * *}$ & & $10.14^{* *}$ & \\
\hline
\end{tabular}

Note. ${ }^{*} p<0.05,{ }^{* *} p<0.01,{ }^{* * *} p<0.001$.

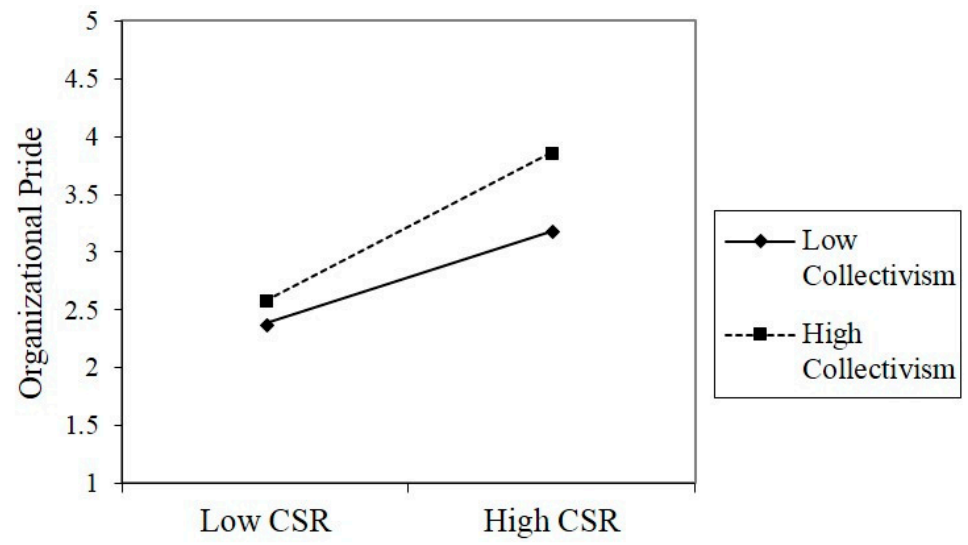

Figure 2. Relationship between CSR perception and organizational pride moderated by collectivism. 


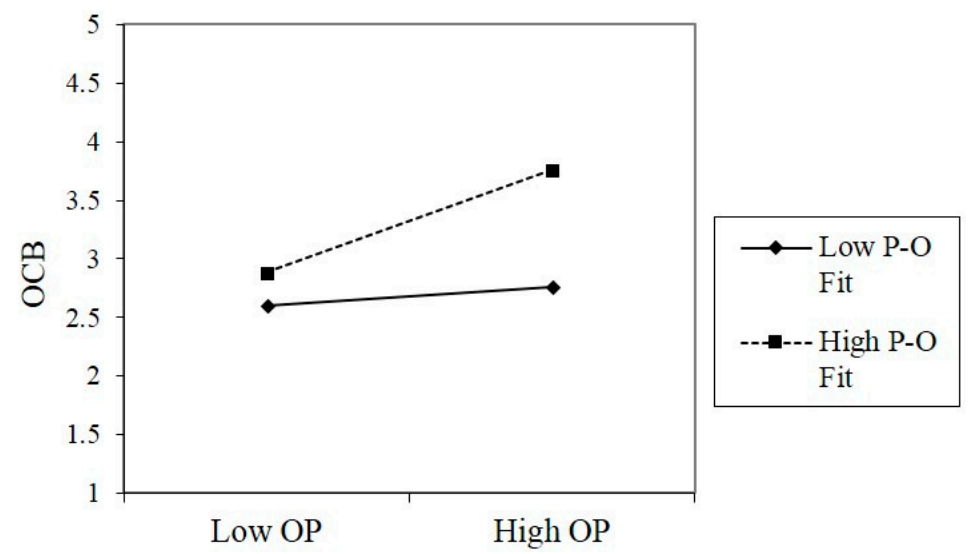

Figure 3. Relationship between organizational pride and OCB moderated by $\mathrm{P}-\mathrm{O}$ fit.

\section{Discussion and Conclusions}

Based on social identity theory [6], we examined a research model linking CSR perception to OCB that included organizational pride as a mediator, and collectivism and $\mathrm{P}-\mathrm{O}$ fit as moderators. Our results revealed that perceived CSR was positively associated with the organizational pride experienced by employees, and organizational pride served as a psychological mechanism that explained the process of CSR perception, leading to OCB. Furthermore, the results indicated a positive interaction between CSR perception and employee's collectivism orientation in predicting organizational pride. Additionally, in predicting employees' OCB from organizational pride, the moderation effect of $\mathrm{P}-\mathrm{O}$ fit was supported.

Our research makes a valuable contribution to enriching our understanding about the benefits of a company's efforts to engage in CSR activities. First, while prior research on CSR perception has paid more attention to its impacts on external stakeholders, our research focused on internal stakeholders (i.e., employees). We found that a company's CSR activities can influence employees' feelings toward their organization, and furthermore their willingness to perform constructive behavior for their organization.

Despite increasing interests in the role of CSR perception in influencing employee behavior, relatively less efforts have been exerted to explore the underlying psychological mechanism. By demonstrating the mediation effect of organizational pride, we can explain why and how perceiving the CSR activities of the employer drives specific individual behavior. An individual's cognitive perception (i.e., CSR perception) can change his/her emotional experience (i.e., organizational pride), which in turn brings about a certain behavior (i.e., OCB). By identifying the cognitive-emotional antecedents of employee behavior, this research enabled us to take a more balanced perspective.

Another important contribution of this research lies in examining individual difference variables as moderators. Most of the prior research attended to contextual variables in an attempt to understand the situational circumstances under which the existing relationship becomes stronger or weaker. Along with situational variables, individual differences should be considered to enhance our ability to predict employee behavior. The present study investigated two individual difference variables-collectivism and $\mathrm{P}-\mathrm{O}$ fit-and tested how they interacted with other factors. First, we expected that employee's collectivism orientation as an individual characteristic, not as a national culture, would affect the relationship of CSR perception and organizational pride. Regardless of whether a person lives in a collectivistic or individualistic society, collectivists tend to think of themselves as a part of group that they identify with, and pursue the goals and benefits of the group more significantly than individualists [10]. When employees with high (versus low) collectivism orientation perceived that their company implemented CSR activities that are beneficial for society, they experienced a higher level of organizational pride. This is because employee knowledge that their organization builds 
up a good reputation through CSR activities can boost their self-esteem through their social identity, which is associated with that group.

In addition, we expected that another individual difference variable, $\mathrm{P}-\mathrm{O}$ fit, would play an important role in predicting employees' actual behavior. Employees who feel that their personal values align well with organizational values tend to accept and follow the implicit message sent by the organization. Perceiving employer's efforts to be a socially responsible member in the global community would impact on employee decisions to embrace the message and engage in OCB at work when the employee perceive a good P-O fit. In sum, this research contributes to the CSR literature by stressing the importance of employees' value orientation and value congruence in eliciting desired outcomes.

The findings of this research have some practical, managerial implications as well. Considering the positive impact of employees' CSR perception on OCB, leaders and managers should actively communicate and share the information on the CSR activities of their employer. The heightened awareness will promote constructive behavior among employees. Furthermore, it should be noted that this expected benefit from CSR perception would be stronger for employees with collectivism orientation and a good P-O fit. Therefore, through efforts to understand individual employee's value orientation and value congruence (between personal value and organizational value), leaders and managers will be able to take a more individualized approach in stressing the employer's responsible behavior and promoting citizenship behavior by enhancing organizational pride.

Despite these contributions, the current study has some limitations in terms of research methodology. First, the main limitation of the present study lies in the single source issue. Our data were collected from employees' self-reports. As we relied on employee self-reports to measure all of the variables in our study, our data is vulnerable to common method bias [61]. Future studies should collect data from different sources to address this concern. Another limitation stems from the measurement tools of CSR perception. The present study employed a CSR perception measure that was designed to capture one's overall perception about a company's CSR activities in general. Some researchers have developed more specific measures that cover multiple sub-dimensions of CSR activities [14]. If future research uses these domain-specific measures (e.g., economic, legal, ethical, philanthropic), we would be able to learn which domain/sub-category of CSR activities would have a more significant influence on employee behavior. Lastly, the endogeneity issues should be considered. When the input variables are associated with the error terms in a regression model, it can cause biased estimates and the endogeneity problem $(\mathrm{Li}, 2016)$ [62]. To address the endogeneity issues, a variety of psychometric methods should be employed. However, we were not able to provide those results in this study. Future research needs to consider a more sophisticated research design or provide additional results with sensitivity analysis, ensuring a stronger construct validity.

Author Contributions: Conceptualization, H.J. and E.Y.O.; Formal analysis, I.-J.P.; Investigation, E.Y.O.; Methodology, H.J. and E.Y.O.; Supervision, H.J.; Writing-original draft, E.Y.O.; Writing一review \& editing, H.J. and I.-J.P.

Conflicts of Interest: The authors declare no conflict of interest. 
Appendix Survey Questionnaire

\begin{tabular}{|c|c|c|c|c|c|}
\hline \multirow[t]{2}{*}{ CSR Perception } & \multicolumn{3}{|l|}{ Very Low } & \multicolumn{2}{|c|}{ Very High } \\
\hline & 1 & 2 & 3 & 4 & 5 \\
\hline \multicolumn{6}{|c|}{ My company helps solving social problems. } \\
\hline \multicolumn{6}{|c|}{ My company participates in public beneficial activities. } \\
\hline \multicolumn{6}{|c|}{$\begin{array}{l}\text { My company perceives public services, sponsorship donations, and voluntary works as an important part of } \\
\text { organizational activities. }\end{array}$} \\
\hline \multicolumn{6}{|c|}{$\begin{array}{l}\text { My company plays as a role of corporate citizen in addition to the pursuit of economic profits of the } \\
\text { corporation. }\end{array}$} \\
\hline \multirow[t]{2}{*}{ Organizational Pride } & \multicolumn{3}{|l|}{ Very Low } & \multicolumn{2}{|c|}{ Very High } \\
\hline & 1 & 2 & 3 & 4 & 5 \\
\hline \multicolumn{6}{|c|}{ I am proud of being a member of my company. } \\
\hline \multicolumn{6}{|c|}{ I feel proud of telling other people that I am being a part of my company. } \\
\hline \multicolumn{6}{|c|}{ I would be very glad to be identified as a representative figure that reminds of our company's image. } \\
\hline \multicolumn{6}{|c|}{ I am proud to tell others about our company. } \\
\hline \multirow[t]{2}{*}{ Organizational Citizenship Behavior } & \multicolumn{2}{|l|}{ Very Low } & & \multicolumn{2}{|c|}{ Very High } \\
\hline & 1 & 2 & 3 & 4 & 5 \\
\hline
\end{tabular}

Helps others even though there is no formal request.

Don't waste the office hours with personal business.

Helps others who have been absent.

Helps others who have heavy workloads.

Goes out of way to help new employees.

Attendance at work is above the norm.

Gives advance notice when unable to come to work.

Don't waste the time unnecessarily during the working time.

\begin{tabular}{llrrrrr} 
Person-Organization Fit & Very Low & \multicolumn{3}{c}{ Very High } \\
\hline
\end{tabular}

The values I preferred is consistent with our company's organizational values.

Company adaptation is hard for me because my values differ greatly from company's values.

I don't have any burden for keeping my values in our company.

My personal goals match with organizational goals of the company.

Overall, I am a highly compatible person with our company.

\begin{tabular}{|c|c|c|c|c|c|}
\hline \multirow{2}{*}{ Collectivism } & \multicolumn{3}{|l|}{ Very Low } & \multicolumn{2}{|c|}{ Very High } \\
\hline & 1 & 2 & 3 & 4 & 5 \\
\hline If a coworker gets a prize, I would feel proud. & & & & & \\
\hline I feel good when I cooperate with others. & & & & & \\
\hline The well-being of my coworkers is important to me. & & & & & \\
\hline
\end{tabular}




\section{References}

1. Harari, M.B.; Reaves, A.C.; Viswesvaran, C. Creative and innovative performance: A meta-analysis of relationships with task, citizenship, and counterproductive job performance dimensions. Eur. J. Work Organ. Psychol. 2016, 25, 495-511. [CrossRef]

2. Katz, D. The motivational basis of organizational behavior. Behav. Sci. 1964, 9, 131-146. [CrossRef] [PubMed]

3. Organ, D.W. Organizational Citizenship Behavior: The Good Soldier Syndrome; Lexington Books: Lexington, MA, USA, 1988; ISBN 0669117889.

4. Muhammad, A.H. Perceived organizational support and organizational citizenship behavior: The case of Kuwait. Int. J. Bus. Adm. 2014, 5, 59-72. [CrossRef]

5. Pierce, J.L.; Gardner, D.G.; Cummings, L.L.; Dunham, R.B. Organization-based self-esteem: Construct definition, measurement, and validation. Acad. Manag. J. 1989, 32, 622-648. [CrossRef]

6. Tajfel, H. Social categorization, social identity, and social comparison. In Differentiation between Social Groups: Studies in the Social Psychology of Intergroup Relations; Academic Press: London, UK, 1978; ISBN 0126825505.

7. De Roeck, K.; El Akremi, A.; Swaen, V. Consistency matters! How and when does corporate social responsibility affect employees' organizational identification? J. Manag. Stud. 2016, 53, 1141-1168. [CrossRef]

8. Lee, S.Y.; Seo, Y.W. Corporate social responsibility motive attribution by service employees in the parcel logistics industry as a moderator between CSR perception and organizational effectiveness. Sustainability 2017, 9, 355. [CrossRef]

9. Yilmaz, A.K.; Ali, I.; Flouris, T. The effects of corporate social responsibility on pride in membership, job satisfaction and employee engagement. Br. J. Econ. Manag. Trade 2015, 9, 1-12. [CrossRef]

10. Triandis, H.C.; Gelfand, M.J. Converging measurement of horizontal and vertical individualism and collectivism. J. Personal. Soc. Psychol. 1998, 74, 118-128. [CrossRef]

11. Brammer, S.; Millington, A.; Rayton, B. The contribution of corporate social responsibility to organizational commitment. Int. J. Hum. Resour. Mang. 2007, 18, 1701-1719. [CrossRef]

12. Tuzzolino, F.; Armandi, B.R. A need-hierarchy framework for assessing corporate social responsibility. Acad. Manag. Rev. 1981, 6, 21-28. [CrossRef]

13. Albinger, H.S.; Freeman, S.J. Corporate social performance and attractiveness as an employer to different job seeking populations. J. Bus. Ethics 2000, 28, 243-253. [CrossRef]

14. Carroll, A.B. The pyramid of corporate social responsibility: Toward the moral management of organizational stakeholders. Bus. Horiz. 1991, 39-48. [CrossRef]

15. Ali, I. Influence of corporate social responsibility on development of corporate reputation and customer purchase intentions. Rom. Rev. Soc. Sci. 2011, 1, 19-27.

16. Sen, S.; Bhattacharya, C.B.; Korschun, D. The role of corporate social responsibility in strengthening multiple stakeholder relationships: A field experiment. J. Acad. Market. Sci. 2006, 34, 158-166. [CrossRef]

17. Boezeman, E.J.; Ellemers, N. Pride and respect in volunteers' organizational commitment. Eur. J. Soc. Psychol. 2008, 38, 159-172. [CrossRef]

18. Glavas, A.; Kelley, K. The effects of perceived corporate social responsibility on employee attitudes. Bus. Ethics Q. 2014, 24, 165-202. [CrossRef]

19. Williams, L.J.; Anderson, S.E. Job satisfaction and organizational commitment as predictors of organizational citizenship and in-role behaviors. J. Manag. 1991, 17, 601-617. [CrossRef]

20. Smith, C.A.; Organ, D.W.; Near, J.P. Organizational citizenship behavior: Its nature and antecedents. J. Appl. Psychol. 1983, 68, 653-663. [CrossRef]

21. Evans, W.R.; Goodman, J.M.; Davis, W.D. The impact of perceived corporate citizenship on organizational cynicism, OCB, and employee deviance. Hum. Perform. 2010, 24, 79-97. [CrossRef]

22. Bandura, A. Social Learning Theory, 1st ed.; Prentice-Hall: Englewood Cliffs, NJ, USA, 1977; ISBN 0138167443.

23. Tracy, J.L.; Robins, R.W. Emerging insights into the nature and function of pride. Curr. Dir. Psychol. Sci. 2007, 16, 147-150. [CrossRef]

24. Lea, S.E.G.; Webley, P. Pride in economic psychology. J. Econ. Psychol. 1997, 18, 323-340. [CrossRef]

25. Helm, S. A matter of reputation and pride: Associations between perceived external reputation, pride in membership, job satisfaction and turnover intentions. Br. J. Manag. 2013, 24, 542-556. [CrossRef] 
26. Jones, D.A. Does serving the community also serve the company? Using organizational identification and social exchange theories to understand employee responses to a volunteerism programme. J. Occup. Organ. Psychol. 2010, 83, 857-878. [CrossRef]

27. Scott, S.G.; Lane, V.R. A stakeholder approach to organizational identity. Acad. Manag. Rev. 2000, 25, 43-62. [CrossRef]

28. Carmeli, A.; Tishler, A. The relationships between intangible organizational elements and organizational performance. Strateg. Manag. J. 2004, 25, 1257-1278. [CrossRef]

29. Dutton, J.E.; Dukerich, J.M. Keeping an eye on the mirror: Image and identity in organizational adaptation. Acad. Manag. J. 1991, 34, 517-554. [CrossRef]

30. Tyler, T.R.; Blader, S.L. Autonomous vs. comparative status: Must we be better than others to feel good about ourselves? Organ. Behav. Hum. Dec. 2002, 89, 813-838. [CrossRef]

31. Bouckaert, G.; Victor, L. Pride and performance in the civil service: The Flemish case. Int. Rev. Adm. Sci. 2001, 67, 65-76. [CrossRef]

32. Gouthier, M.H.J.; Rhein, M. Organizational pride and its positive effects on employee behavior. J. Serv. Manag. 2011, 22, 633-649. [CrossRef]

33. Rioux, S.M.; Penner, L.A. The causes of organizational citizenship behavior: A motivational analysis. J. Appl. Psychol. 2001, 86, 1306-1314. [CrossRef] [PubMed]

34. Parkes, L.P.; Bochner, S.; Schneider, S.K. Person-organization fit across cultures: An empirical investigation of individualism and collectivism. Appl. Psychol. 2001, 50, 81-108. [CrossRef]

35. Moorman, R.H.; Blakely, G.L. Individualism-collectivism as an individual difference predictor of organizational citizenship behavior. J. Organ. Behav. 1995, 16, 127-142. [CrossRef]

36. Hofstede, G. Motivation, leadership, and organizations: Do American theories apply abroad. Organ. Dyn. 1980, 9, 42-63. [CrossRef]

37. Triandis, H.C.; McCusker, C.; Hui, C.H. Multimethod probes of individualism and collectivism. J. Personal. Soc. Psychol. 1990, 59, 1006-1020. [CrossRef]

38. Singelis, T.M.; Triandis, H.C.; Bhawuk, D.P.S.; Gelfand, M.J. Horizontal and vertical dimensions of individualism and collectivism: A theoretical and measurement refinement. Cross-Cult. Res. 1995, 29, 240-275. [CrossRef]

39. Kim, J.-I.; Park, P. Different effects of CSR types on corporate reputation: Moderating effect of individualism and collectivism. Korean J. Adv. 2014, 25, 53-80.

40. Kim, C.H.; Amaeshi, K.; Harris, S.; Suh, C.-J. CSR and the national institutional context: The case of South Korea. J. Bus. Res. 2013, 66, 2581-2591. [CrossRef]

41. Stipek, D. Differences between Americans and Chinese in the circumstances evoking pride, shame, and guilt. J. Cross. Cult. Psychol. 1998, 29, 616-629. [CrossRef]

42. Katz, D.; Kahn, R.L. The Social Psychology of Organizations, 2nd ed.; Wiley: Hoboken, NJ, USA, 1978; pp. 1-23. ISBN 0471023558.

43. Chatman, J.A. Improving interactional organizational research: A model of person-organization fit. Acad. Manag. Rev. 1989, 14, 333-349. [CrossRef]

44. Boon, C.; Den Hartog, D.N.; Boselie, P.; Paauwe, J. The relationship between perceptions of HR practices and employee outcomes: Examining the role of person-organisation and person-job fit. Int. J. Hum. Resour. Manag. 2011, 22, 138-162. [CrossRef]

45. Muchinsky, P.M.; Monahan, C.J. What is person-environment congruence? Supplementary versus complementary models of fit. J. Vocat. Behav. 1987, 31, 268-277. [CrossRef]

46. Kristof, A.L. Person-organization fit: An integrative review of its conceptualizations, measurement, and implications. Pers. Psychol. 1996, 49, 1-49. [CrossRef]

47. O'Reilly C.A., III; Chatman, J. Organizational commitment and psychological attachment: The effects of compliance, identification, and internalization on prosocial behavior. J. Appl. Psychol. 1986, 71, 492-499. [CrossRef]

48. Lauver, K.J.; Kristof-Brown, A. Distinguishing between employees' perceptions of person-job and person-organization fit. J. Vocat. Behav. 2001, 59, 454-470. [CrossRef]

49. O' Reilly, C.A., III; Chatman, J.; Caldwell, D.F. People and organizational culture: A profile comparison approach to assessing person-organization fit. Acad. Manag. J. 1991, 34, 487-516. [CrossRef] 
50. Cable, D.M.; DeRue, D.S. The convergent and discriminant validity of subjective fit perceptions. J. Appl. Psychol. 2002, 87, 875-884. [CrossRef] [PubMed]

51. Verquer, M.L.; Beehr, T.A.; Wagner, S.H. A meta-analysis of the relationships between person-organization fit and work attitudes. J. Vocat. Behav. 2003, 63, 473-489. [CrossRef]

52. Maignan, I.; Ferrell, O.C. Corporate social responsibility and marketing: An integrative framework. J. Acad. Mark. Sci. 2004, 32, 3-19. [CrossRef]

53. Yoon, K.; Ryu, J.Y. A study on the internal marketing effects of CSR activities: The mediating effect of corporate reputation on employees' job satisfaction, organizational identification and organizational citizenship behavior*. J. Public Relat. Res. 2011, 15, 41-76.

54. Lee, K.G.; Cho, Y.H. The effects of pride and respect on the relationship between abusive supervision of supervisors and follower's organizational citizenship behaviors and turnover intention. Korean J. Hum. Resour. Manag. 2013, 37, 65-92.

55. Boezeman, E.J.; Ellemers, N. Volunteering for charity: Pride, respect, and the commitment of volunteers. J. Appl. Psychol. 2007, 92, 771-785. [CrossRef] [PubMed]

56. Du, Z.; Cho, Y.H. The effect of ethical leadership on organizational citizenship behavior-The mediating role of moral identity. J. Hum. Resour. Manag. Res. 2015, 22, 277-293. [CrossRef]

57. Choi, B.I.; Jang, C.H.; Kwun, S.K. The effects of person-organization fit and person-job fit on organizational effectiveness. Korean J. Hum. Resour. Manag. 2011, 35, 199-232.

58. Baron, R.M.; Kenny, D.A. The moderator-mediator variable distinction in social psychological research: Conceptual, strategic and statistical considerations. J. Personal. Soc. Psychol. 1986, 51, 1173-1182. [CrossRef]

59. Preacher, K.J.; Hayes, A.F. SPSS and SAS procedures for estimating indirect effects in simple mediation models. Behav. Res. Methods Instrum. Comput. 2004, 36, 717-731. [CrossRef] [PubMed]

60. Aiken, L.S.; West, S.G. Multiple Regression: Testing and Interpreting Interactions, 1st ed.; Sage Publications Inc.: Newbury Park, CA, USA, 1991; ISBN 0761907122.

61. Podsakoff, P.M.; Mackenzie, S.B.; Lee, J.Y.; Podsakoff, N.P. Common method biases in behavioral research: A critical review of the literature and recommended remedies. J. Appl. Psychol. 2003, 88.5, 879-903. [CrossRef] [PubMed]

62. Li, F. Endogeneity in CEO power: A survey and experiment. Investig. Anal. J. 2016, 45, 149-162. [CrossRef] 